\title{
Negotiating food systems resilience
}

To the Editor - The COVID-19 pandemic has brought food systems into sharp focus. Governments, private sector companies, and civil society organizations alike are asking what they can do to enhance food systems resilience to shocks like this and ongoing stresses like climate change. As systems thinkers, we believe that answers to these questions are best generated by a mindset that embraces emergence. With this mindset, we expect some interventions will be top-down and policy-based but know that most will be unpredictable and depend on the free-willed behaviour of multiple actors and resulting inter-actor dynamics. In this way, we see resilience as an emergent characteristic of the system.

We can encourage resilience to emerge, if we understand what resilience is sought. To do this, we need to ask: "resilience of what?", "to what?", "for whom?", and "over what time period?" . These four questions help to define the boundaries ${ }^{2,3}$ of the systemic resilience sought; they point to the inclusion, exclusion, and marginalization of certain stakeholders and the issues that concern them. Since the answers are a matter of perspective, the pursuit of resilience by one actor may undermine the resilience of another and lead to contestation. Post-pandemic emergence of food systems resilience will require anticipating that contestation and dealing with it head-on. Food businesses, it seems, may be increasingly expected to lead in this regard.

COVID-19 swept the globe shortly after the World Economic Forum's Davos Manifesto $2020^{4}$ called on all business leaders to shift from a historical adherence to shareholder capitalism to a widening acceptance of stakeholder capitalism. Larry Fink, CEO of BlackRock, heeded the call with his decision to exit "investments that present a high sustainability-related risk" 5 just before the pandemic broke. However, because of the way these risks are managed, it does not necessarily follow that a reduction in sustainability risk will encourage the emergence of systemic resilience.

Enhancing resilience means moving beyond sustainability to see systems of interest, receive their feedback, and make informed interventions ${ }^{6}$. For food businesses, the adoption of stakeholder capitalism means seeing profoundly expanded systems of interest. The 'of what, to what, for whom, over what time period?' is broader and longer in the frame of stakeholder capitalism. This calls for a new dynamic; one that is grounded in the power of the interactions between stakeholders and systems actors. This new dynamic can be thought of as negotiating food systems resilience.

Negotiated resilience is an evolving concept. It includes an enhanced focus on process, inclusivity and participation. Recognizing the "inevitability of contestation and politics" , negotiated resilience does not aim for consensus. Rather, it foregrounds key trade-offs and power dynamics, expecting iterative engagement over time and governance scales. From the perspective of a food business, negotiating resilience can be a collective act of systems thinking, which then raises a fifth question of resilience: "who to negotiate resilience with?"

To start, food businesses can adopt a systems approach to stakeholder identification ${ }^{8}$, and from there focus on marginalized stakeholders most impacted by the pandemic shock. Pre-pandemic consolidation and efficiency maximization in the US meatpacking industry, for example, stifled adaptive capacity and accentuated racial inequalities when the shock hit. These and other trends contributed to spikes in food waste, food insecurity and COVID-19 infection rates 9 . Such failures are fodder for innovation and critical conversations about equity, both of which could spark the emergence of food systems resilience.

Decision-makers at all levels in food businesses need to ask themselves penetrating questions about how they understand the food systems they shape. How might they help to balance power by working with and through more inclusive institutions? If business leaders truly seek to eliminate 'sustainability-related' risks, they need to think beyond sustainability metrics that maintain a faulty status quo and introduce a new dynamic by calling stakeholders to the table to negotiate resilience.

Angela R. Hansen (D) $1{ }^{凶}$, John S. I. Ingram (D) 2 and Gerald Midgley $3,4,5,6,7,8$

${ }^{1}$ University of Cape Town, Cape Town, South Africa.

${ }^{2}$ University of Oxford, Oxford, UK. ${ }^{3}$ University

of Hull, Hull, UK. ${ }^{4}$ Linnaeus University, Växjö,

Sweden. ${ }^{5}$ Mälardalen University, Eskilstuna, Sweden.

${ }^{6}$ Victoria University of Wellington, Wellington, New

Zealand. ${ }^{7}$ University of Canterbury, Christchurch,

New Zealand. ${ }^{8}$ University of Queensland, Brisbane,

Queensland, Australia.

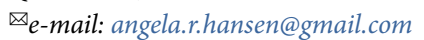

Published online: 15 September 2020

https://doi.org/10.1038/s43016-020-00147-y

References

1. Helfgott, A. Eur. J. Oper. Res. 268, 852-864 (2018)

2. Churchman, C. W. The Systems Approach (Dell, 1979).

3. Ulrich, W. Critical Heuristics of Social Planning: A New Approach to Practical Philosophy (Wiley, 1994).

4. Schwab, K. Davos Manifesto 2020: The universal purpose of a company in the fourth industrial revolution. World Economic Forum (2 December 2019); https://go.nature.com/318FVGr

5. Fink, L. A Fundamental Reshaping of Finance (BlackRock, 2020); https://go.nature.com/32e 4c5u

6. Midgley, G. Systemic Intervention: Philosophy, Methodology, and Practice (Kluwer Academic/Plenum, 2000).

7. Harris, L. M., Chu, E. K. \& Ziervogel, G. Resilience 6, 196-214 (2017).

8. Gregory, A. J., Atkins, J. P., Midgley, G. \& Hodgson, A. M. Eur. J. Oper. Res. 283, 321-340 (2020).

9. Gibbins, J. D. et al. Morb. Mortal. Wkly. Rep. 69, 557-561 (2020).

Author contributions

A.R.H. drafted the manuscript. All authors provided critical revision of the manuscript, provided final approval of the version to publish and agreed to be accountable for all aspects of the work.

Competing interests

The authors declare no competing interests. 